\title{
Live Demonstration: Handwritten Digit Recognition Using Spiking Deep Belief Networks on SpiNNaker
}

DOI:

10.1109/ISCAS.2015.7169034

Link to publication record in Manchester Research Explorer

\section{Citation for published version (APA):}

Stromatias, E., Neil, D., Galluppi, F., Pfeiffer, M., Liu, S-C., \& Furber, S. (2015). Live Demonstration: Handwritten Digit Recognition Using Spiking Deep Belief Networks on SpiNNaker. Poster session presented at 2015 IEEE International Symposium on Circuits \& Systems, Lisbon, portugal. https://doi.org/10.1109/ISCAS.2015.7169034

\section{Citing this paper}

Please note that where the full-text provided on Manchester Research Explorer is the Author Accepted Manuscript or Proof version this may differ from the final Published version. If citing, it is advised that you check and use the publisher's definitive version.

\section{General rights}

Copyright and moral rights for the publications made accessible in the Research Explorer are retained by the authors and/or other copyright owners and it is a condition of accessing publications that users recognise and abide by the legal requirements associated with these rights.

\section{Takedown policy}

If you believe that this document breaches copyright please refer to the University of Manchester's Takedown Procedures [http://man.ac.uk/04Y6Bo] or contact uml.scholarlycommunications@manchester.ac.uk providing relevant details, so we can investigate your claim.

\section{OPEN ACCESS}




\title{
Live Demonstration: Handwritten Digit Recognition Using Spiking Deep Belief Networks on SpiNNaker
}

\author{
Evangelos Stromatias*, Daniel Neil ${ }^{\ddagger}$, Francesco Galluppi ${ }^{\dagger}$, Michael Pfeiffer ${ }^{\ddagger}$, \\ Shih-Chii Liu ${ }^{\ddagger}$ and Steve Furber* \\ *Advanced Processor Technologies Group, School of Computer Science, University of Manchester, UK \\ M13 9PL, Manchester, United Kingdom \\ Email: stromate@cs.man.ac.uk \\ ${ }^{\dagger}$ Equipe de Vision et Calcul Naturel, Vision Institute, Université Pierre et Marie Curie \\ UMR S968 Inserm, UPMC, CNRS UMR 7210, CHNO des Quinze-Vingts, Paris, France \\ ${ }^{\ddagger}$ Institute of Neuroinformatics, University of Zurich and ETH Zurich \\ Winterthurerstrasse 190, CH-8057 Zurich, Switzerland
}

\begin{abstract}
We demonstrate an interactive handwritten digit recognition system with a spike-based deep belief network running in real-time on SpiNNaker, a biologically inspired manycore architecture. Results show that during the simulation a SpiNNaker chip can deliver spikes in under $1 \mu \mathrm{s}$, with a classification latency in the order of tens of milliseconds, while consuming less than $0.3 \mathrm{~W}$.
\end{abstract}

Associated Track 8.1: Neural Networks and Systems: Spiking Neural Network circuits and systems

\section{Demonstration}

Deep neural network architectures such as Deep Belief Networks (DBNs), are a very active research topic in machine learning and achieve state-of-the-art classification results. However, simulating large-scale DBNs has large computational demands, which means high energy requirements and long latencies, and thus limits their use in real-time applications for mobile or robotic platforms. A recently published study [1] developed the theory to map an offline-trained DBN into a spiking neural network composed of Leaky Integrateand-Fire (LIF) neurons, exploiting the so-called Siegert approximation for the firing rate of an LIF neuron. Spiking neural networks running on an appropriate hardware platform can allow asynchronous and massively parallel energy-efficient processing [2]. SpiNNaker [3] is a biologically-inspired manycore scalable architecture designed to enable large-scale simulations of heterogeneous models of spiking neurons efficiently and in real-time. In this demonstration, we show an application of SpiNNaker as a real-time event-based hardware prototyping platform to enable interactive handwritten digit recognition with a spiking deep belief network.

\section{Demonstration SETUP}

The demonstration setup consists of a four-chip SpiNNaker board [3], a wireless router, a laptop, and a mobile device which for the purpose of this demonstration is a tablet device, Fig 1. The user interface, which runs on the mobile device, allows the user to draw a digit and receive the classified output of the spiking deep belief network running on SpiNNaker.

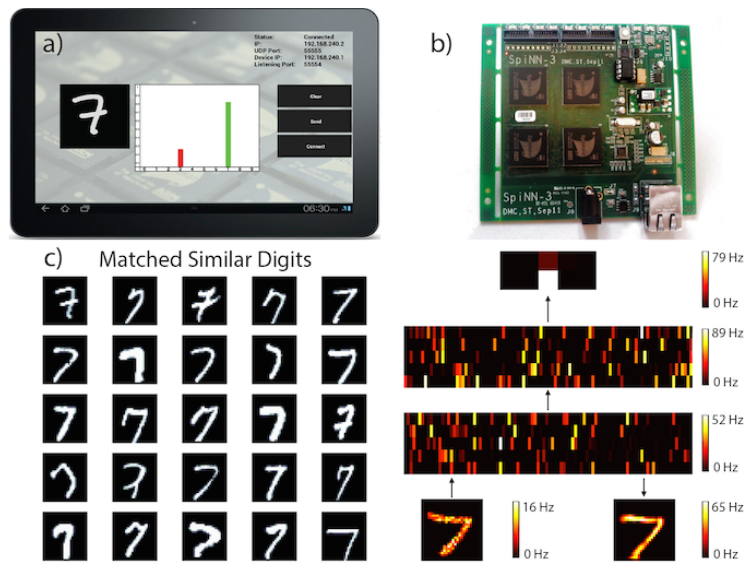

Fig. 1. Handwritten digit recognition setup. a) The user interface running on a mobile device, showing a finger-drawn digit (left) and a correct classification. b) A 4-chip SpiNNaker board. c) The output of the laptop monitor, showing network-classified similar digits from the training set, as well as the firing rates of neurons within each layer during classification

\section{VISITOR EXPERIENCE}

Visitors can draw digits using a tablet and the spikebased DBN will run on SpiNNaker in real-time producing a result within tens of milliseconds, while dissipating less than $0.3 \mathrm{~W}$ power. The classified output will be presented on the tablet as a normalised histogram of the spikes of the output population. In particular, they will see the conversion of static images to spike-trains, the propagation of neural spikes through multilayer spiking DBNs, and the resulting output of a correctly-classified handwritten digit. Additionally, the network recognizes different styles of handwriting accurately.

\section{REFERENCES}

[1] P. O'Connor, D. Neil, S.-C. Liu, T. Delbruck, and M. Pfeiffer, "Realtime classification and sensor fusion with a spiking deep belief network," Frontiers in Neuroscience, vol. 7, no. 178, 2013.

[2] D. Neil and S.-C. Liu, "Minitaur, an event-driven fpga-based spiking network accelerator," IEEE Transactions on Very Large Scale Integration (VLSI) Systems, vol. PP, no. 99, pp. 1-1, 2014.

[3] S. Furber, F. Galluppi, S. Temple, and L. Plana, "The SpiNNaker project," Proceedings of the IEEE, vol. 102, no. 5, pp. 652-665, May 2014. 